\title{
Algo más acerca de Lázaro e Ibiza y algún que otro contemporáneo, sobre la base principal de varias cartas a Pau de González Fragoso
}

\author{
M. LAÍNZ, S. J. \\ Av. Hermanos Felgueroso, 25, ES-33205 Gijón, España \\ E-mail: mlainzg@yahoo.es \\ Editor: N. Ibáñez
}

Recibido 17 de agosto de 2012; Aceptado 21 de agosto de 2012

\begin{abstract}
SOME MORE INFORMATION ABOUT LÁZARO E IBIZA AND OTHER CONTEMPORARIES, MAINLY BASED ON SEVERAL LETTERS to Pau from González Fragoso.- Basically, judgments uttered by Dr. R. González Fragoso criticizing Prof B. Lázaro's expertise in mycology, collected from his letters to Dr. C. Pau conserved at the Botanic Institute of Barcelona.

Key words: correspondence; historical archive; history of botany.

\section{Resumen}

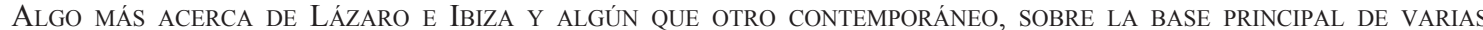
Cartas a Pau de González Fragoso.- Fundamentalmente, juicios emitidos por el Dr. R. González Fragoso acerca del Prof. B. Lázaro como inatendible micólogo, espigados en las cartas del primero al Dr. C. Pau conservadas en el Institut Botànic de Barcelona.

Palabras clave: archivo histórico; correspondencia; historia de la botánica.
\end{abstract}

A mis no escasas referencias a Lázaro en el terreno botánico s. str. - $-\mathrm{y}$ frente a más de un extracto epistolar de Mateo (1996) - vine pensando en hacer otras en el terreno, que no es el mío, de lo micológico. Tan solo me retraía la dificultad para mí —estos años últimos - de llegarme a Barcelona, en el archivo de cuyo Institut Botànic sigue depositado el epistolario de Pau en cuestión; pero las buenas digitalizaciones, recibidas ahora, me deciden a publicar en Collectanea Botanica este modesto aunque no inútil artículo.

Vengamos a las comunicaciones primeras (tarjetas y breves cartas) de Romualdo González Fragoso a Pau que Mateo (1996: 240) lista —y a las que, ló- gicamente, se refiere de modo previo el cuerpo de su trabajo-, de interés aquí muy relativo. Rompen fuego las cartas del 4-III-1912 y 3-X-1913, que doy por meras tomas de contacto y ni siquiera he pedido me digitalizaran. Subsiguen las comunicaciones invernales del año último (27-XI, 29-XI, 7-XII, 11-XII y 20-XII-1913) —que solo en parte conozco íntegras, pero que dejan claro que Pau está en plan de colaborar, lo que también aclaran las inmediatas publicaciones del micólogo en Madrid-; aunque no sea fácil más de una vez hacer de «adivino» — para Pau ni para nadie — ante materiales indeterminables prácticamente. 
4-III-1914. ¡Fecha de una carta que se le pasó por completo a Mateo (1996: 100, 240)! En los párrafos que transcribo - he omitido algunos igualmente carentes aquí de interés- González Fragoso tira contra la Botánica madrileña; de lo que se deduce que Pau le ha puesto en el disparadero... Que hay sintonía en asuntos varios —v. gr., preocupación por que suba el nivel científico en España-, quedará bien probado a lo largo de las transcripciones ulteriores - una pizca trabajosas ellas, por el desaliño «literario» del firmante y otros detalles acerca de los que no merece la pena extenderse.

\section{Sr. D ${ }^{n}$ Carlos Pau}

Segorbe

Muy querido amigo: he tenido el gusto de recibir su trabajo "Sobre alg[unos] veg[etales] cur[iosos]", que he visto con gusto, pues me temo voy á tener que hacerme algo fanerogamista, robando tiempo a mis hongos, para no tener que sufrir á esta canalla.

Recibo también [...]

Dentro de pocos dias podré enviarle el trabajo que envié á la Soc. de H. N. del cual ya he corregido ha dias las pruebas. Al remitirmelas me mandaron una nota del Sr. Buen, diciendome que el Cistus ladaniferus (Barcelona) que era de Ud. no existia alli. Las hojas son de Cistus, pero comparadas con otras que tengo de C. ladaniferus no me parecen identicas, $y$ he puesto en el trabajo Cistus sp. Á los hongos no se atrevía ni á mirar la ortografia, pero en fanerogamia cuando pueden salir como sabios criticos mirando unos libracos procuran lucirse. Hay pues que tener mucho cuidado con esto.

El Uromyces [...]

Había pensado no decirle nada del Cistus ladaniferus, pero como supongo sea un lapsus de la pluma, creo no se molestará por ello, pues yo por mi parte hago el mismo caso de los gritos de esos gansos interrumpidos en su sueño, que de oir llover cuando estoy bajo techado.

Si como pienso paso algunas semanas esta primavera en la Sierra de esta provincia, le mandaré fanerogamas, y asi me ahorraré trabajos de determinación de ellas. Aqui en los alrededores como $U d$. ha herborizado tiene ya lo que hay que no es gran cosa por lo interesante.
Sabe suyo muy afmo $y$ verd. ${ }^{\circ}$ a. ${ }^{o}$ S.s. qsme Romualdo Gz. Fragoso [rubricado]

S/c Lineros 21 Sevilla 4/3 -914

PS. Me piden con gran empeño del Labor. de Cryptogam[i]e de Paris algunos ejemplares de Isoetes baetica, Cheilanthes hispanica, y otro helecho que no conozco (Allosurus? /Pozoi, este creo de Cataluña. Seguramente tendrá Ud. las tres especies, y le agradeceria muchisimo al menos un ejemplar de cada una con su etiqueta correspondiente $p^{a}{ }^{a}$ remitirselas á nombre de Ud.; si Ud. desea algun ó algunos helechos, licopodiaceas ó isoetaceas á cambio las pediré, á fin de que su molestia no resulte infructuosa. Tendria mucho gusto en complacer á aquellos buenos amigos á quienes molesto diariamente, y que tuvieron la paciencia de aguantarme año y medio, poniendo el laboratorio y las colecciones á mi disposición, lo que nunca hicieron ni aun con el ilustre Laz., de quien se rien á mandibula batiente, por su ignorancia y presunciones de ciencia.

22-III-1914. Carta de la que sí dice algo el extracto de Mateo (1996: 100), aunque proceda hoy completárselo no poco, a más de intercalar en lo que se transcribe del texto una leve indicación y la correspondiente cita. Omitimos, por el contrario, lo que no viene al caso.

\section{Sr. D. ${ }^{n}$ Carlos Pau}

Segorbe

Muy quer. ${ }^{o} .^{\circ}$ y colega: no le he escrito antes, esperando ver si contestaba de Madrid, acerca de lo del Cistus, pero el amigo Odón parece haberse quedado como dicen aqui "cual gallo que traga uva”, y no dice ni pio. Como última prueba remito un trabajo consultado planta por planta, asegurado de incendio, pero en el cual van media docena de especies nuevas, y algunas especies africanas citadas por vez primera en Europa ${ }^{2}$, circunstancias graves que molestarán muchisimo á aquellos sabios sesudos, y académicos botánicos, que creen deben

\footnotetext{
${ }^{2}$ Dentro de alguna vaguedad, es evidente se refiere al artículo de González Fragoso (1914a) aparecido con rapidez.
}

\footnotetext{
${ }^{1}$ Pau (1914).
} 
aparecer las especies nuevas como los cometas, con rabo, para poderlas ellos ver.

A la menor obgeccion retiro el trabajo lo mando á otra parte, y juro á Dios, que voy á demostrar que algunos pasando por sabios son verdaderos mamarrachos, que corrompen á la juventud con libros de texto que debieran ser quemados por estupidos, en vez de servir para enriquecer á hombres frescos y desahogados, por académicos que sea ó quieran ser. $[\ldots]^{3}$

La Sphaceloteca [sic!] Schweinfurtiana (Thüm) Sacc sobre Imperata, es especie que yo no tenia, que Laz. me enseñó procedente de Valencia (Boscá) $y$ le determiné de memoria, pero como está tan retrasado la publicó con el nombre de Ustilago Schweinfurtiana Thüm dado por Th. hace 40 años, y creyendo q.e era una especie de Egipto cuando es común entre otras partes en el mediodia de Francia é Italia. Sus ejemplares me servirán para darle esta pequeña lección á ver si consigo estimularlo y que estudie algo.

$[\ldots]^{4}$

Y no le canso mas. Mande lo que guste a su amigo verd. ${ }^{\circ} y$ afno

Romualdo G. Fragoso [rubricado]

S/c Lineros 21 $22 /$. $^{\text {zo }} 914$

26-XI-1914. «Nuevos detalles sobre sus hongos microscópicos y nuevas críticas a Lázaro». ¡Eso es todo lo que dice Mateo (1996: 104) en su extracto!

\section{Sr. D. ${ }^{n}$ Carlos Pau}

Segorbe

Muy querido amigo: recibo con verdadero placer su grata y los ejemplares que me envía y que agradezco mucho. De nada debe darme gracias pues la dedicatoria es bien pequeña muestra del agradecimiento que le debo, y bien justa correspondencia á su colaboración generosa. El Phomopsis Pau me parece muy interesante y seguramente por ahi no dejará de encontrarse sobre Xanthium el Diaporthe á que corresponda. De las [otras plantas] que hoy me remite, $[\ldots]$

\footnotetext{
${ }^{3}$ Se prescinde aquí de tres parrafitos.

${ }^{4}$ Se prescinde aquí ulteriormente de casi una carilla.

${ }^{5}$ González Fragoso (1914b: 433-434).
}

$[\ldots]^{6}$

Lazaro tuvo un exabrupto estos meses pasados y estuvo tan disparatado que no me tomé el trabajo de contestarle. En el extrangero me preguntaron algo acerca de lo que le pasaba, y lo contesté francamente. Pienso pasar en Madrid una larga temporada, no se cuando todavía, y sentiré que estando yo alli se le revuelvan las bilis, pues apesár de todo no puedo olvidar lo tuve por amigo muchos años, y siento todo lo ocurrido y lo que pudiera ocurrir, por el mas que por mí.

\section{Sabe es suyo muy afm. ${ }^{\circ}$ a..$^{\circ}$ y verd $^{o}$ G. Fragoso [rubricado] \\ S/c Lineros 21 \\ Sevilla 26/XI-914}

Párrafo este segundo en el que González Fragoso menciona su amistad, larga, con Lázaro Ibiza, del que tan mal viene hablado y veremos que - salvo en el forzadísimo elogio fúnebre de 1921, tan ineludible como antes imprevisible - lo sigue haciendo indefinidamente. Doy por evidente - ¿bastará como «evidencia» remitirme a Ryvarden \& Calonge (1976: 155-156)? - que no lo hace tan solo por congraciarse con Pau, decidido enemigo de Colmeiro y escuela. Deudas de gratitud, sí es posible que algunas tuviese con Lázaro - posteriores a la vuelta de su primitiva estancia en París, cuando aterrizó en Madrid con éxito más bien pasajero, en plena y prometedora juventud (1883-1885)—, porque no parece del todo inverosímil que algo pintase allí Lázaro —catedrático universitario desde 1892 y académico de la Real de Ciencias desde 1900cuando en 1911 y 1912 la Junta de Ampliación de Estudios pensionó a González Fragoso para que se pusiese al día otra vez en el extranjero. Los «reconocimientos de amistad» de tal índole carecen del más mínimo peso como prueba de nada.

4-XII-1914. «Sobre sus mutuos envíos de micromicetos y comentarios a los táxones concretos». Eso es todo lo que dice Mateo (1996: 104), como en el caso anterior. El párrafo que a continuación transcribo íntegro no debe olvidarse, aunque suponga poca novedad.

\footnotetext{
${ }^{6}$ Se prescinde aquí de tres largos párrafos completos.
} 
Sr. D. ${ }^{n}$ Carlos Pau

Segorbe

Muy quer. ${ }^{\circ}$ amigo: he recibido con verdadero agradecimiento los lindos ejemplares [...]

$[\ldots]^{7}$

Aunque el amigo Beltrán piense dedicarse á los Uredales de esa región, no por ello renuncio yo al menos á tenerlos en mi herb. ${ }^{\circ}$ para el dia de mañana, pues poco he de vivir si no le doy al buen Lazaro el gusto de ver una flora de los Uredales de España sin los errores que el ha sabido recopilar, aunque tenga otros de mi propia cosecha.

$[\ldots]^{8}$

Sabe es suyo muy afmo verd ${ }^{\circ}$ a aradecido amigo y colega

R. Gonz. ${ }^{z}$ Fragoso

[rubricado]

S/c Lineros

Sevilla 4/XII-914

\section{$[\ldots]^{9}$}

Beltrán me escribió diciendome tenia algunos pirenomicetes que Ud. le habia dado para mi, y que ya me los enviaria un dia de estos, pero aun no los recibí.

14-XII-1914. Carta carente de interés muy especial, en el caso. Mateo (1996: 104), por cierto, al extractárnosla, da la impresión de no tenerla delante, o casi. Lo de «bueno y modesto», dicho del Prof. Caballero, me suena; pero no es en esa carta -que solo mienta su «gran afición» botánica- donde figura. Lo de «arrogantes e incompetentes como Lázaro y Beltrán» dista de ser lo que allí se dice de sus connivencias personales. Y lo de que González Fragoso censure «que Font envíe plantas a Lázaro, quien se va quedando sólo y ya no cuenta con casi ningún recolector» viene del único pequeño párrafo que aquí transcribo.

El farmacéutico militar Sr. Font no le conozco, $y$ dado su elogio, siento muchisimo envie plantas á Lazaro, hoy casi reducido á Escribano y a Font pues Tortosa no le mandará mucho, y Boscá creo que en lo sucesivo tampoco.

\footnotetext{
${ }^{7}$ Se prescinde aquí de otra carilla de las cuatro.

${ }^{8}$ Se prescinde aquí de otro párrafo intrascendente.

${ }^{9}$ Tras la rúbrica viene una última carilla, micológica, la

que acaba con el parrafito aquí transcrito.
}

Lo que hay es que Font, cuyo futuro profesional en esa lejanísima época no estaba claro en Barcelona, buscaba el apoyo alternativo de Madrid: nos lo dicen suficientemente los extractos de algunas de sus cartas a Pau hechos por Mateo - v. gr., los de las del 7-X-1914, 1-XI-1914, 10-II-1915 y 25-V-1915.

24-XII-1914. Carta que también se inicia con pormenores micológicos de los que por sistema seguimos olvidándonos: el extracto algo amplio de Mateo (1996: 104-105) viene a iluminarse con los últimos párrafos, aquí transcritos. La final declaración del firmante pone suficientemente de relieve su independencia económica, y su altura científica de miras.

Y paso á los botánicos. Baste decirle que fuí juez en las oposiciones de Caballero y Beltrán, y que conservo notas detalladas de ellas. Estuvieron los dos mal, Beltrán peor ¿pero que hacer? Comparados con los opositores de otras catedras de Botánica eran dos sábios, aquellas catedras del Botánico! Yo solo podia juzgar la parte de Criptogamia y le aseguro que algas y hongos, que les tocaron á ambos, no sabian una palabra los dos. ¿Pero es posible exigir en España Fanerogamia y Criptogamia, sobre todo la segunda que no ha saludado ningun $D^{r}$ en Ciencias?

De Fanerogamia, en el practico fueron á la par, por el error del Melittis Melissophyllum á que Ud se refiere, Beltrán no pudo ni aun con el genero del Bromus mollis; las demas especies igual los dos, y las criptogamas todas equivocadas, en genero, en familia, en orden, en todo. En la lección Caballero estuvo mucho mejor que Beltrán, y esto decidió. ¿Es fanerogamista? No lo afirmaré pero le aseguro que tiene aficion, - despues de obtenida la catedra,y esto hace perdonar muchos pecados, puede ser botánico, está á tiempo.

De la trapacería madrileña sé yo acaso mas que Ud. Los que publican especies, y cuando se las piden del extrangero no las envían solo merecen el triste juicio que Ud. hace con justicia. Asi los juzgan por ahí, pero en cambio ellos se rien de mi y de Ud., viven, pasan por sabios en España, y guardan buenos billetes en el Banco alguna que otra vez, y hasta se hacen ricos pongo Lazaro por ejemplo. Desengañese son mas sabios que Ud. y que yo, saben mas, y ya es tarde para que sigamos mejor camino. Yo por mi parte solo quiero seguir 
con mis hongos, no tengo hijos, y ni mi mujer, ni mi madre ni mis hermanos, les hace falta mi herencia, se contentan con que no emplee en hongos su dinero sino el mio solo. Y basta de jaqueca.

Suyo amigo verdadero Romualdo Gz. Fragoso [rubricado]

S/c Sevilla 24-XII-914

31-XII-1914. «Comenta sus vinculaciones con Madrid, a donde va pensionado de vez en cuando a estudiar cosas concretas. Recomienda a Pau no aceptar un puesto allí, pues por lo que le pueden ofrecer no vale la pena dejar su casa y su farmacia». Extracto integral de Mateo (1996: 105).

Tras uno de los habituales «exordios micológicos» de González Fragoso, prosigue así la carta:

\section{[...] Y pasado esto reanudo nuestra conversacion.}

Nuestra situacion es algo diversa, y ademas yo soy bastante transigente mientras no se me ataca injustamente, y aun soy capaz de perdonar el ataque si es justo.

En la situacion de Ud. ¿que podria ofrecerle el Sr. Bolivar que compensara el abandonar su casa y su farmacia? Nada, y como nada le hubiese á $U d$ convenido calló. A mi en cambio cuando me ofrece 300 ó 350 ptas mensuales para hacer un estudio fuera de este rincon, me indemniza de lo que aqui dejo de ganar, y sin alterar mucho mi presupuesto puedo dedicarme unos meses á mi vicio favorito, sin sentir lo que gasto ni lo que pierdo, y además doy un disgusto á algunos. He estado hace no mucho 9 meses en el extrangero con mi mujer que es tambien algo botánica, lo suficiente para ayudarme algo, y me costó muchos miles de pesetas y perdí casi otras tantas. En cambio pasé luego año y medio pensionado por la Junta de Ampliacion de estudios, $y$ en ese año y medio gasté solo un par de miles de mi bolsillo, y nada perdí, pues lo perdido estaba compensado por la pension. Crea Ud que D. ${ }^{n}$ Ignacio, á quien conozco hace 33 años, es hombre de bastante talento, y no ofreceria ni á Ud. ni a mi una limosna. Se la dá á quien no merece otra cosa $y$ ademas la pide poco menos que con lagrimas en los ojos y puedo citarle á Ud. nombres. El defecto grande del Sr. Bolivar es la debilidad de no saber decir no a nadie, hasta que abusan demasiado. En estas cosas de botánica está llevado de un buen deseo digno de alabanza, y si pudiera tenerlo á
Ud. en Madrid y de el dependiera estoy seguro no le escatimaria nada. Si otra cosa le dicen á $U d$. diga que mienten, y suelen mentir los que luego le mendigan a el mas. Crea Ud. que si Font y Quer tratase con Bolivar en vez de tratar con Lazaro conseguiria mas, y sin detrimento. Lazaro me ofrecio trabajar en su Laboratorio con el sueldo de 300 ptas, y ni le conteste nunca mas, ni he vuelto á hablarle. ¿Sabe Ud. por que? Por que la condicion era publicar poco, y bajo su direccion, y asi no quiero ni el sueldo de Presidente del Consejo. El Sr. Bolivar me concede los medios que pido me deja trabajar á mi gusto y se satisface solo con saber que trabajo, cuando me pagan y cuando no me pagan, cuanto puedo. El no está acostumbrado á ver eso en los demás, y los que crean engañarle se engañan ellos, y conozco y Ud conoce varios burladores burlados.

Y paso á otra cosa. Amigo mio yo no haré la flora micologica española que tendrá al menos 5 ó 6 millares de especies, soy viejo para ello y no encuentro nada hecho. He perdido 20 años viendo enfermos, que gracias a mis pasadas intransigencias, y gracias á que mi mujer decidió dejarme solo reducido a dos horas de consulta, dispongo ahora de tiempo para botaniquear iDios se lo premie! Y no vá mas por hoy.

Feliz año nuevo, y no se canse Ud. de plantas para bien de la ciencia, y menos de los amigos y de este suyo afmo y verd. ${ }^{\circ}$

$$
\begin{array}{r}
\text { R. Gonz[ález]Fragoso } \\
\text { [rubricado] } \\
\text { S/c Lineros } 21 \\
\text { Sevilla 31/XII-914 }
\end{array}
$$

PS. Me han dicho que Lázaro prepara un botanico, no me han dicho el nombre, contra mi, así como los alemanes el mortero de 42. Supongo no será el Sr. Font Quer, sino algun desgraciado que necesita vivir.

¡Más otro post scriptum o posdata en lo que se nos presenta como apéndice a esta larga carta de fin de año - una octavilla de la consulta sevillana de nuestro médico, sin fecha-, la que se inicia en el reverso, detrás de unos parrafitos micológicos numerados! Lo que por comienzo se dice ahí, sí parece que tiene que ver con las breves líneas que se dedican al Prof. Lázaro en esa carta del 31-XII: 
P.S. Tengo á estas hora 1.200 especies de hongos microscopicos españoles. Lazaro recopilando lo de todos y lo suyo, apenas si llegó en su flora á 250 y unos 20 que ha publicado después. Ya ve Ud. si tiene motivos para quererme mal, cuando yo pensaba que mi herb. fuera á el de Farmacia. Y ya vé Ud. si ha trabajado en 30 años de micologo oficial, académico, y sabio eminente. Hay para reir, ó para llorar segun los caracteres. ;Ah! Tengo unas hojas parasitadas por Pucc. Carduorum de Beltrán que me las envió como de Silybum Marianum, y que seguramente son de Carduus. Si es broma pudo pasar! Si es equivocación..... ${ }^{10}$

Dos palabras acerca de lo que la carta dice de Bolívar, padre. Nadie, por cierto, dudó nunca de su categoría como entomólogo. Es asimismo evidentísimo que hizo mucho por elevar el nivel de las publicaciones científicas madrileñas, para lo que no le faltaron apoyos oficiales de importancia. Bien estudiado está lo hecho siendo él directivo de la Junta de Ampliación de Estudios. En el caso de Romualdo González Fragoso, fue acierto grande acabar trayéndosele a Madrid - itres décadas después de su primer empleo en el Museo como «conservador», apenas acabada la estancia en París que sufragaría su familia!- en lo que D. Ignacio, como es claro, dirigió la recuperación de un talento. Entiendo menos bien alguna de las explicaciones que ahí esboza el micólogo, pero sí perfectamente que Pau jamás renunciase a su áurea independencia en Segorbe, por carácter... y por estrategia bastante bien perceptible: ¿no acabó consiguiendo importantes apoyos, de varios tipos? Acerca de Bolívar, algo he publicado —Laínz (2001: 125-134, 2002: 163-170)—: tanto Pau como el P. Navás le manifestaron siempre notable respeto. González Fragoso, como acabamos de ver, habla de treinta y tres años de trato, de su clarividencia frente a la investigación vocacional y de sus intenciones dignas de loa.

9-I-1915. (Fig. 1). «Le da cuenta de sus últimos enfrentamientos con Lázaro. "No soy tan bueno como $v$. imagina pero me gusta dar la batalla donde me la presentan". Más noticias sobre problemas en

\footnotetext{
${ }^{10}$ Esos cinco puntos rematan el post scriptum, de mala manera, en dos líneas añadidas en el margen del anverso.
}

las altas esferas madrileñas». Extracto integral de Mateo (1996: 105).

\section{Sr. D. ${ }^{n}$ Carlos Pau}

Segorbe

Querido amigo: recibi su grata del 3 que no quiero dejar de contestar.

No soy tan bueno como Ud. imagina, pero me gusta dar la batalla donde me la presentan. Lázaro quiso lanzarme de la Soc. esp. y yo lo he lanzado á el de la Comision de publicación. Aun quiso servirse de Odón como portavoz, y el revolcón (del Cistus ladaniferus) ha sido mayúsculo. El trabajo mio que el rechazó se publicó, y si algo he retirado de él ha sido para darle un revolcón mayor, que el no se espera por cierto. Mis trabajos se han publicado además con los del Museo, $y$ he ido otra vez a la Est. ${ }^{n}$ Alpina, solo por que se permitió no quererlo. Aun le guardo mas, pues quiero hacerle comprender que es un pobre bougre que ha podido pasar por que han querido dejarlo. Está Ud. equivocado en creer tenga actualmente nada que ver en el Museo, todo lo contrario. Lo que hoy se hace de botánica en el Museo, bien ó mal, con laudable esfuerzo de D. ${ }^{n}$ Ignacio, es una acusación contra el Laboratorio de Lázaro, y las practicas legendarias que implantó Colmeiro en el Botánico, y que hoy siguen allí como en Farmacia.

Su trabajo de Ud. sería bien recibido en todas partes seguramente. Lazaro hoy no es quien para oponerse á nada. Yo siento que haya dado lugar á esto; solo por este sentimiento puede $U d$. creerme bon homme.

Beltrán me escribió y mandó algunos pirenomicetes de Ud. y suyos. Me dice le han concedido un premio de 400 ptas por sus recolecciones de fanerogamas del verano pasado. Me alegra la noticia pues deseo trabaje todo el que pueda, si trabaja bien, y él está en buena edad para poder hacerlo.

$Y$ paro aquí, para desearle buena excursión á Roncesvalles, buenas cacerías, y algunas plantas de camino, y que yo las vea.

Sabe es suyo a. ${ }^{\circ}$ verd. ${ }^{\circ}$ G. Fragoso [rubricado]

S/c Lineros 21 Sevilla 9-I-1915

P.S. Le advierto no pensé nunca que Font y Quer fuera el testaferro de Lazaro. Suponia que en tal caso no seria amigo de Ud. Le hice á Ud. la indi- 
cacion de mi anterior por que siendo su amigo, si desea algo, debe aconsejarle otro camino que el de Lazaro. Por ahí hoy no se vá á ninguna parte, ni aun mereciendolo en justicia. Esto aparte de que si es hombre de valer es lastima se inutilice y Lazaro no quiere á su lado nadie util mas que á condicion de ser ductil y maleable. Es un Colmeiro pequeño, caricaturesco, lo creí con mas talento iDios me perdone el error!

Lo de los «últimos enfrentamientos», queda muy claro. Lo de las «noticias sobre problemas en las altas esferas madrileñas», vemos que se reduce por parte de González Fragoso a subrayar que, «bien o mal», es en el Museo madrileño, donde se hace «lo que hoy se hace de botánica» en Madrid y donde radican los poderes naturalísticos.

16-IV-1916. Carta que, tras más de un año, en el epistolario subsigue a la precedente, y que Mateo (1996: 111) extracta con bastante amplitud aunque sin acierto excesivo. Tiene para mí un doble interés. Vamos, por de pronto, a su transcripción - y a iluminar algo esas críticas a Lázaro con las oportunas citas bibliográficas.

\section{Sr. D. ${ }^{n}$ Carlos Pau,}

Segorbe

Muy quer. amigo: con verdadero placer recibo su grata que me envian desde mi casa de Madrid; no así su trabajo pues dejé encargado solo me reespidiesen las cartas. Allí lo encontraré pronto, pues para el 5 ó 6 de Mayo, pienso volver despues de hacer unas excursiones que necesito para recolectar "cagaditas de moscas" que me interesan asi como á algunos micologos de Pirineos allá.

El trabajo de Persia es en efecto una leccion $p^{a}{ }^{a}$ Laz., pues Escalera, que estaba engañado como tantos otros, á su vuelta de Persia le dió algunos hongos, acompañados por cierto de dibujos, á los cuales después de mucho tiempo, de exagerar dificultades, etc, puso varios nombres equivocados, y no llegó nunca á publicarlos porque sabia demás que sus determinaciones no debian darse á luz. La publicacion de estos debe haberle producido estupor profundo, como á todo el que no entiende una cosa.

Pero la mas dura lección es la Nota que supongo en su poder sobre hongos ó micromicetos de Melilla, esta si bien poquísimo interesante, pero en la que, admitiendo su Puccinia Withaniae, de
Malaga, le rechazo la descripcion y se la rectifico por completo, demostrandole asi que ni cuando cae en su mano una especie nueva con rabo que son las unicas que puede conocer, es capaz de bien describirla ni diferenciarla, y que tal como la dió es "mutatis mutand[is"] la Puccinia Atropae Mont., de Canarias, mientras que descrita con sinderesis es especie nueva.

Ahora se ha refugiado en los Poliporáceos, pero ni aun ahi pienso dejarlo, y he comenzado á reunir materiales, para cuando los publique, entrar yo en ellos. Ya sabe Ud. por tanto que los Poliporáceos que encuentre serán bien recibidos, pero que vengan en alguna cantidad, sin preparación alguna, y solo con indicacion exacta del sustrato.

Beltrán me remitió en consulta 40 uredales, entre ellos una especie nueva; dice tiene otros tantos pero no se dá prisa á enviarlos, y me temo lo que Ud. presagia, que ni aun así llegue á publicarlos.

Es un triste pais este, de gente nula, ó sin entusiasmos ni alientos para nada, y alzados sobre este monton de.... cuatro audaces, sin conocimientos, como Lazaro, pasando por sabios para la mayoria, cuando sus obras pregonan y prueban su ignorancia hasta el punto de hacer reir.

¿Que le hemos de hacer? Vivamos á nuestro modo lo que nos quede, que el tiempo hará justicia.

Sabe le quiere su amigo R. Gz. Fragoso [rubricado]

S/c Lineros 21

Sevilla 16/IV-916

Desde el 8 de Mayo, Madrid S/c Eloy Gonzalo 14, pral

«El trabajo de Persia» es — contra lo que insinúa Mateo en su parentético primer inciso, dubitativo- no el futuro de Pau \& Vicioso (1918), sino el del propio González Fragoso (1916a) cuyo subtítulo y párrafos introductorios aclaran ya por completo la cuestión de los Martínez de la Escalera y su viaje al Oriente Medio en 1899, y también hubiesen aclarado a Mateo en el punto dicho; hacia el final, supone su extracto que «Lázaro ha publicado una nota sobre hongos de Melilla», siendo así que firma la nota González Fragoso (1916b: 337) en cuya página que ahí se indica figuran las referidas enmiendas a esa $« P$. Withaniae Láz.»; la cual Puccinia estaba publicada ya por Lázaro (1913: 16). 


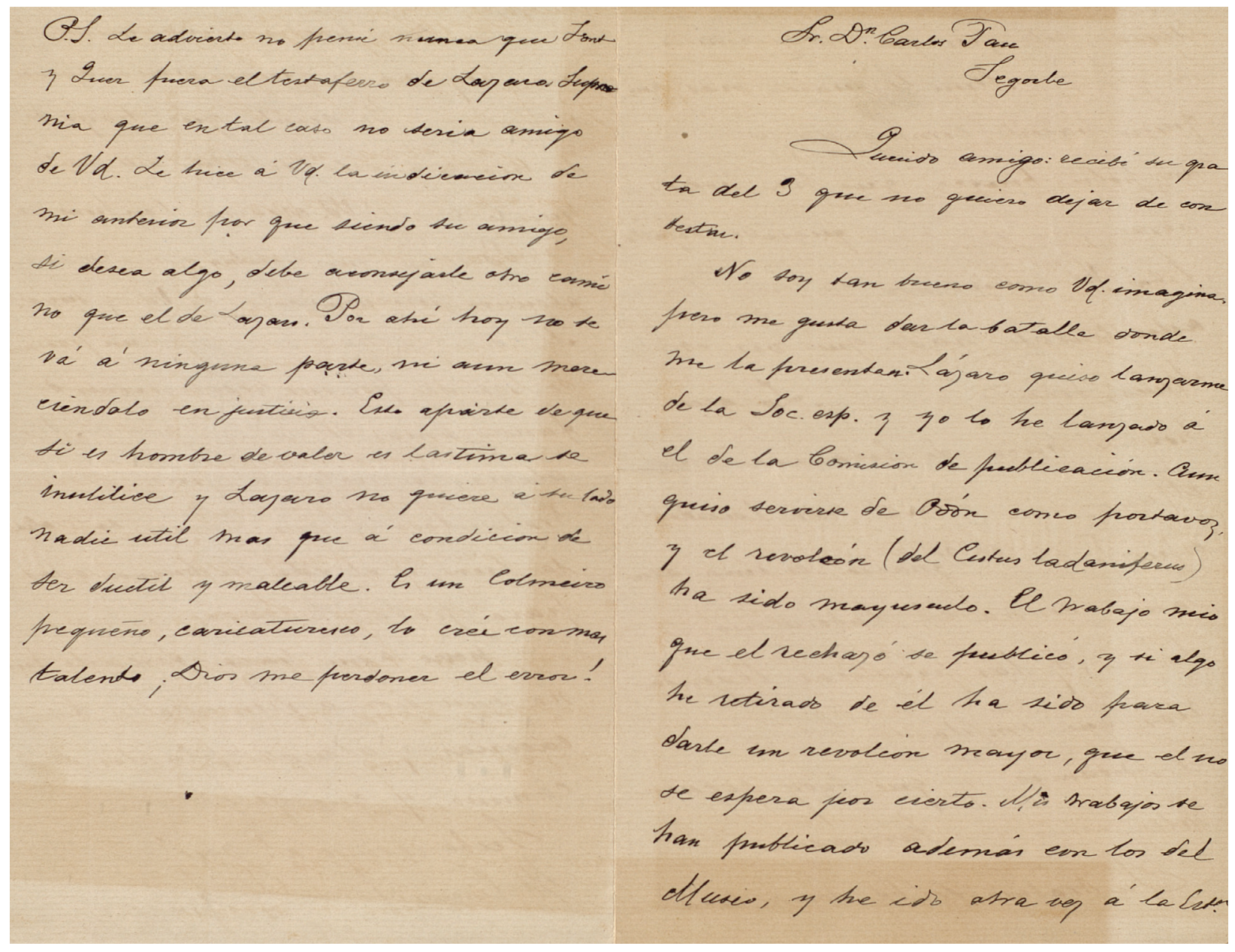

Figura 1. Carta de González Fragoso a Pau del 9 de enero de 1915. Archivo del Institut Botànic de Barcelona.

Además, esa carta deja detallada constancia de que nuestro sevillano, definitivamente, se había ido a vivir a Madrid y trabajar en el Museo, tras lo medio anunciado - e incluso desaconsejado al de Segorbe - a finales de 1914 y comienzos de 1915. Recuérdense dos pasajes transcritos páginas atrás. «Pienso pasar en Madrid una larga temporada, no se cuando todavía», dijo ya el 26-XI-1914, lo que doy por un primer indicio de que insinuaba tentadoras propuestas la dirección del Museo. El 24-XII-1914, remataba su carta subrayando la independencia económica de que disfruta y que para él es la vida seguir con sus hongos. Siente uno desconocer la rápida ulterior contestación de Pau al que González Fragoso el día último del año 1914 casi hace confesión general, aunque susceptible acaso de interpretaciones, como las anteriores confidencias. Echaba ese 31-XII por delante lo de que D. Ignacio
Bolívar no podría ofrecer al activo estudioso de los vegetales vasculares nada que valiese la pena. Explicaba luego lo de sus habituales idas a Madrid, medianamente subvencionadas, y hasta recordaba seguidamente - sin «arrepentirse», como es lógico- lo de que la Junta de Ampliación de Estudios, en 1911 y 1912, le había pensionado para reciclarse una vez más en el extranjero. Por fin, admitamos que lo de sus invectivas finales, dentro de la extrema dureza o franqueza del estilo, no constituye novedad especial en el «monólogo» que nos ocupa.

18-V-1916. «Comentarios sobre la flora madrileña y los recientes artículos de Pau al respecto [Pau, $1915,1916]^{11}$. Se lamenta del poco conocimiento que sobre ella tienen los catedráticos de la capital».

${ }^{11}$ Ambos trabajos de Pau se incluyen en el apartado de Referencias Bibliográficas (N. del E.). 


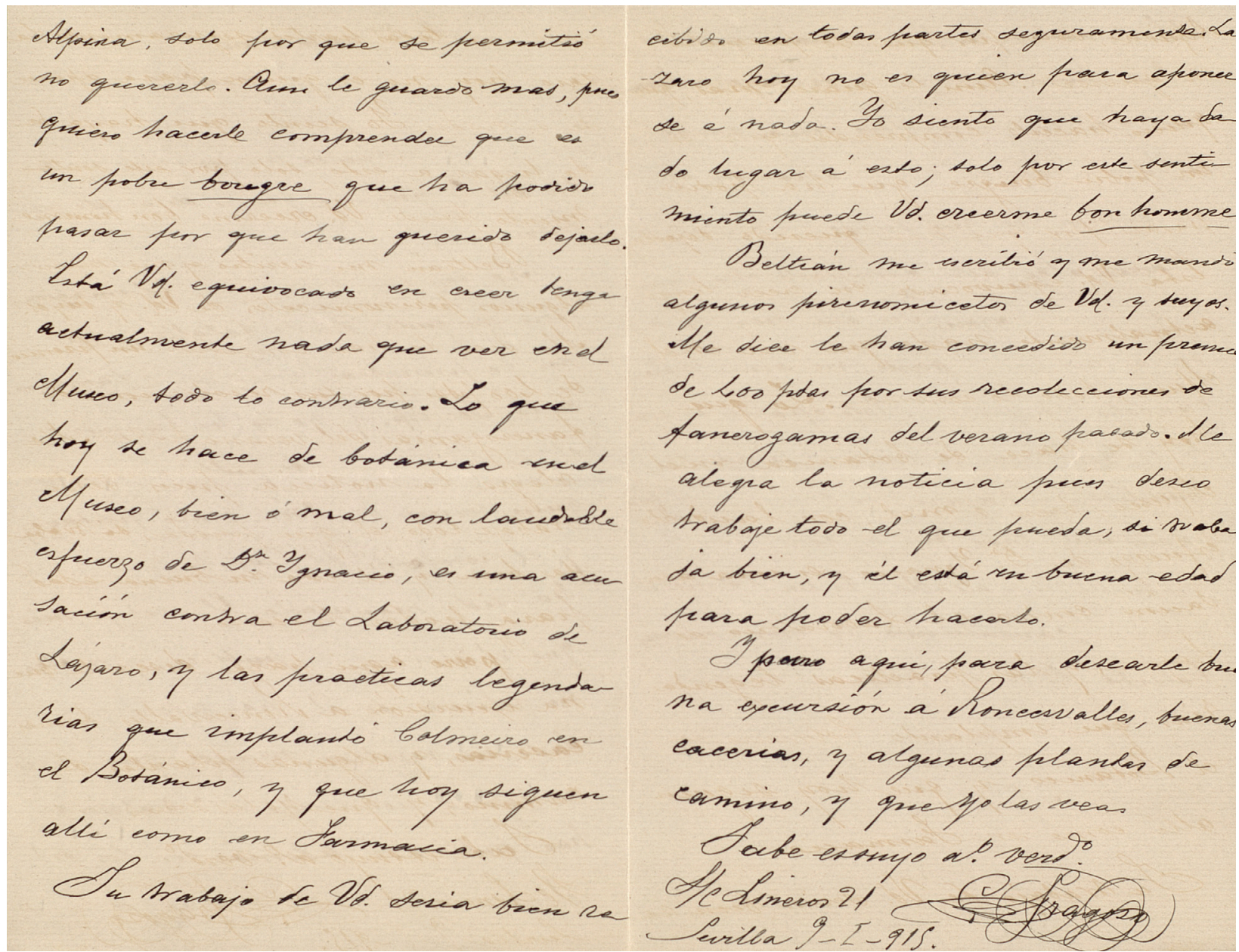

Figura 1. (Cont.)

Eso es todo lo que dice Mateo (1996: 112).

\section{MUSEO DE CIENCIAS NATURALES HIPÓDROMO (MADRID)}

\section{Sr. D. ${ }^{n}$ Carlos Pau \\ Segorbe}

Querido amigo: apenas llegué á Madrid lei sus tres notas acerca de la flora de Madrid bien estudiada por Lazaro, Gredilla ... y demás eminencias, sin contar los que fueron. ¿Si esto es la de Madrid que serán las demás provincias?

$$
[\ldots]^{12}
$$

\footnotetext{
${ }^{12}$ Tras rogarle que le determine una Tamarix, dedica un tercer párrafo muy en particular a las problemáticas etiquetas de Persia que Vicioso le pide adjunte, responsables de algún error toponímico previo. La carta finaliza con la frase que se transcribe a continuación.
}

Esto siempre igual en Botánica, las mismas nulidades, las mismas mezquindades, las mismas envidias, y la ciencia y el amor á ella no parecen por ninguna parte.

Conservese bueno, gracias anticipadas, y mande á su a. $^{\circ}$ verd. ${ }^{\circ}$ Romualdo Gonz. ${ }^{z}$ Fragoso [rubricado] S/c Eloy Gonzalo 14 pral 18/Mayo916

Lo de «Lázaro, Gredilla... y demás eminencias», más que a lamentación huele a simple puyazo anticapitalino; aunque, sin duda, se deploren las consecuencias que lo que pasa en Madrid podrá tener en provincias. Las primeras líneas de lo del final deploran asimismo un fenómeno arraigado en España y en parte del extranjero. 
9-V-1917. (Fig. 2). El extracto de Mateo (1996: 116) dijo tan solo: «Agradece su nota y comentarios sobre leguminosas. Ideas sobre sus futuros viajes».

\section{MUSEO NACIONAL DE CIENCIAS NATURALES MADRID (HIPÓDROMO)}

9. V. 917.

Sr. D. ${ }^{n}$ Carlos Pau

Segorbe

Muy quer. amigo: recibi su grata que agradezco, así como los datos acerca de la sinonimia del Dolichos monachalis, por los que veo que en efecto no andaba lejos de los Phaseolus.

Mucho he sentido tambien no ir á Barcelona, tanto mas cuanto que tenia "kilométrico" para este viage, el cual caducará sin usarlo, a causa de mi desdichada dolencia. Aunque algo mejorado, no desaparece ni mucho menos. Por lo demás en Barcelona, la Junta de Ciencias naturales ha hecho esplendidamente las cosas, y ninguno de los pocos que han ido ${ }^{13}$ ha tenido que gastar $5 \mathrm{cs}$. Todo se lo han encontrado pagado: hotel, excursiones, viage de vuelta, automoviles á la puerta, etc., todo en fin hasta las targetas postales que han adquirido. Hay que reconocer que aquel pueblo asomado á los Pirineos, vé mas cerca á Europa, no á esta salvage de ahora, sino á la otra cientifica y trabajadora. No hay que buscar en el resto de España algo semejante, se encuentran individuos, pero no un pueblo entero, no corporaciones populares que impulsen y ayuden la labor cientifica.

No he sentido en cambio ir á Sevilla. Alli Sampaio presentó un trabajo de liquenes, luego con Lazaro y demas hicieron una justa acerca de la nomenclatuta botánica. No sé que dijeron pero sé no tienen autoridad para arreglar ese asunto, se que no vale la pena de hablar de una cosa que debe juzgarse por el sentido y la ley común, y sé, que, en Micologia al menos, las decisiones y acuerdos del Congreso de Bruselas, nacieron muertas, con el voto en contra de sabios micologos, derrotados por la mayoria aplastante pero no convincente de tres ó cuatro, seguidos de porción de indocumentados como Lazaro, etc. Y por ultimo que alli donde en fin se reunieron los sabios botánicos de todo el mun-

\footnotetext{
${ }^{13}$ De Madrid, según dice Font a Pau en carta fechada el 29-IV, asistieron «a las fiestas Hernandez Pacheco, Cabrera y Cándido Bolivar».
}

do en la nomenclatura micologica se cometieron grandísimos disparates, y que nada se respeta de aquello por que no debe respetarse, y solo queda en pie lo justo que nadie ha legislado por que es de derecho consuetudinario. ¿Qué quiere hacer pues en Sevilla esos dos botánicos y medio? Charlar, pues que charlen. Dentro de dos años publicarán las actas, y reiremos.

Sabe le quiere de veras su $a^{\circ}$

Gz. Fragoso [rubricado]

S/c Eloy Gonzalo 14 pral

12-VII-1917. Mateo (1996: 117) registra de modo escueto la concisa petición que sigue; más, al frente de las comunicaciones del año en curso - por carecer la carta de fecha-, un acuse de recibo del peticionario, amplio, quien allí supone «ya de nuevo en su poder» el préstamo, adelanta juicios —que repetirá con detalle mayor el 19-VIII- y espera que se mande pronto a Pau, del Museo de Historia Natural de Barcelona, «mi trabajo de Cataluña» ${ }^{14}$.

Dr. Romualdo González Fragoso

Eloy Gonzalo, 14, pral.

Madrid 12 Julio 1917

Quer.: $a^{o}:$ mucho le agradeceré me preste, si como creo, los tiene, los siguientes folletos:

Texidor. Apuntes p. ${ }^{a}$ la fl. esp. Barcelona 1869. Y

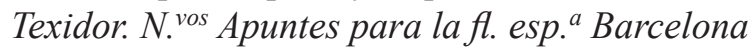
1872.

que puede enviarme certif. ${ }^{\circ}$ y devolveré en igual forma haciendolo yo, y no confiandome de los mozos para que no ocurra lo que con el "Sertum"

Sabe es suyo a.$^{\circ}$ verd. ${ }^{\circ}$

Gz. Fragoso

[rubricado]

19-VIII-1917. «Juicios muy severos sobre los pocos españoles que hasta entonces han escrito sobre hongos, de los que casi ninguno se salva», dice Mateo (loc. nuper cit.); quien, además, transcribe un poquillo del párrafo último, algo libremente.

\footnotetext{
14 De mucha extensión éste, primero de la decena que publicó en la Ciudad Condal y esencialmente quedan ya citados, de modo no muy perfecto, en la bibliografía de Fernández Riofrío (1928: 123-127), más en la básica noticia necrológica de Unamuno (1928: 86-100).
} 


\section{MUSEO NACIONAL DE CIENCIAS NATURALES MADRID (HIPÓDROMO)}

\section{VIII-917}

Sr. D. ${ }^{n}$ Carlos Pau

Segorbe

Muy quer: ${ }^{\circ}{ }^{\circ}$ recibi su grata del 11 á la que contesto, algo retrasado, pues estos [días...] de huelgas y desordenes, han hecho perder tiempo, aun que no he dejado ningun dia de venir al Museo á trabajar.

Carlos regresó de su excursion, algo repuesto. Su padre anda tambien malucho con erisipela.

Con verdadera impaciencia deseo ver su trabajo de Persia, también D. ${ }^{n}$ Ygnacio me pregunta con frecuencia por el.

Creo que en Barcelona no tendrá Ud. dificultad alguna, sino al contrario todo genero de facilidades. Deseo de todas veras vaya Vd. no solo por lo que pueda hacer personalmente, sino por que es de necesidad hacer discipulos, gente que sepa y quiera trabajar, si ha de salir la Botánica de los tiempos calamitosos que para ella han corrido, y aun corren en España. Deseo permanecer en Madrid, por eso mas que por nada; si logro dejar alguien que siga trabajando, daré por bien empleado el costoso sacrificio que representa para mi, y para mi Sra., la estancia en Madrid. Pero si nos vamos y no quedan mas que los discipulos de los Lazaros y Gredillas, que Botánica se hará en España?

No conoci personalmente á Texidor, pero sus notas de Hongos me resultan acertadas, al menos, si bien muy inferiores á lo que al mismo tiempo se hacia en la Fl. port. por Thümen, Winter y otros, que á decir verdad ninguno era lusitano. Comparadas con las de Laz., Rivas Mateos, Lacoizqueta, Ruiz Casaviella, etc., las de Texidor son buenas, con ser algo mas antiguas. Despues de el, y antes mas, ó no se ha dicho nada, ó se han dicho disparates, escritos con tal desenfado, que parece creian sus auctores no iban á ser leidos jamás por un botánico, y escribian solo para su familia ó para analfabetos. No hablo de lo que hizo Loscos, que en Hongos, solo fue un recolector meritorio, no muy secundado por cierto por Rabenhorst, idolo de Lazaro, ${ }^{15}$ que con sus libros ha disparatado terriblemente.

Sin mas por hoy mande á este su $a^{\circ}$ que sabe le quiere

Gz. Fragoso [rubricado]
Olvidemos las cartas que subsiguen. Ya cité otras relacionadas con la subvención que recibió Pau para su viaje marroquí de 1921 —Laínz (2001: 130)—, a un lado alusiones, en la página 129, a los «buenos oficios» de González Fragoso ante Ignacio Bolívar.

Lo que no puede olvidarse al llegar a este punto es la reseña con estrambote (González Fragoso, 1917) que hizo de la obra de Lázaro $(1916,1917)$ «Los Poliporáceos de la flora española». Tras algo así como una página en la que lo irónico asoma tras lo ditirámbico, se propone Lazaroa como nombre genérico para sustituir a Boudiera Lázaro Ibiza nec Cooke (Ascobalaceae) in Grevillea (1877), VI, p. 76, y escuetamente se combinan, bajo Lazaroa, las cinco «especies» lazaroanas del «género», «nueva» esa «Lazaroa scalaria Láz. ex Gonz. Fragoso» cuyo tipo, según Ryvarden \& Calonge (1976: 156), simplemente sería un ejemplar de Phellinus pomaceus (S. F. Gray) Maire. Acto seguido, hace la reseña balance de la obra - no sin clara intención crítica...-, el que rematan breves ditirambos ulteriores. Remataré yo este párrafo recordando que la revista Lazaroa, según Castroviejo (1981: 327), viene siendo publicada por la Facultad de Farmacia de Madrid a partir no de 1979 (fecha de la contraportada: 22 de diciembre de 1979) sino de septiembre de 1980.

Todo, tras 1917, sigue su curso. El amor tan claro del sevillano a su trabajo favorito - ahora, en Madrid, hecho visible a bastantes naturalistas de índole diversa- le lleva en 1920 a la presidencia de la Real Sociedad Española de Historia Natural. En febrero de 1921 - la fecha «29» supone clara errata, quier del archivo parroquial, quier del registro civil o del propio González Bueno (1980: 327) - fallece Lázaro, que había ocupado la presidencia veinte años antes. En la inmediata sesión, del 3 de marzo, a nuestro micólogo heroico le imponen ofrecerse a firmar la correspondiente nota necrológica; más aún: «El Sr. Olea [Subinspector Farmacéutico de Sanidad Militar] pide la palabra para proponer que, dados los méritos extraordinarios del Sr. Lázaro, se permita al Sr. Fragoso dar a la nota referente al eminente profesor mayor extensión que la acostumbrada en este género de trabajos, como así se acuerda» (Anónimo, 1921a: 126). ¿Quién iba cuatro años atrás a decirle que

\footnotetext{
${ }^{15}$ Coma la última, evidentemente, mal puesta: es a Lázaro y no a Rabenhorst a quien ahí se acusa de haber disparatado en sus libros.
} 


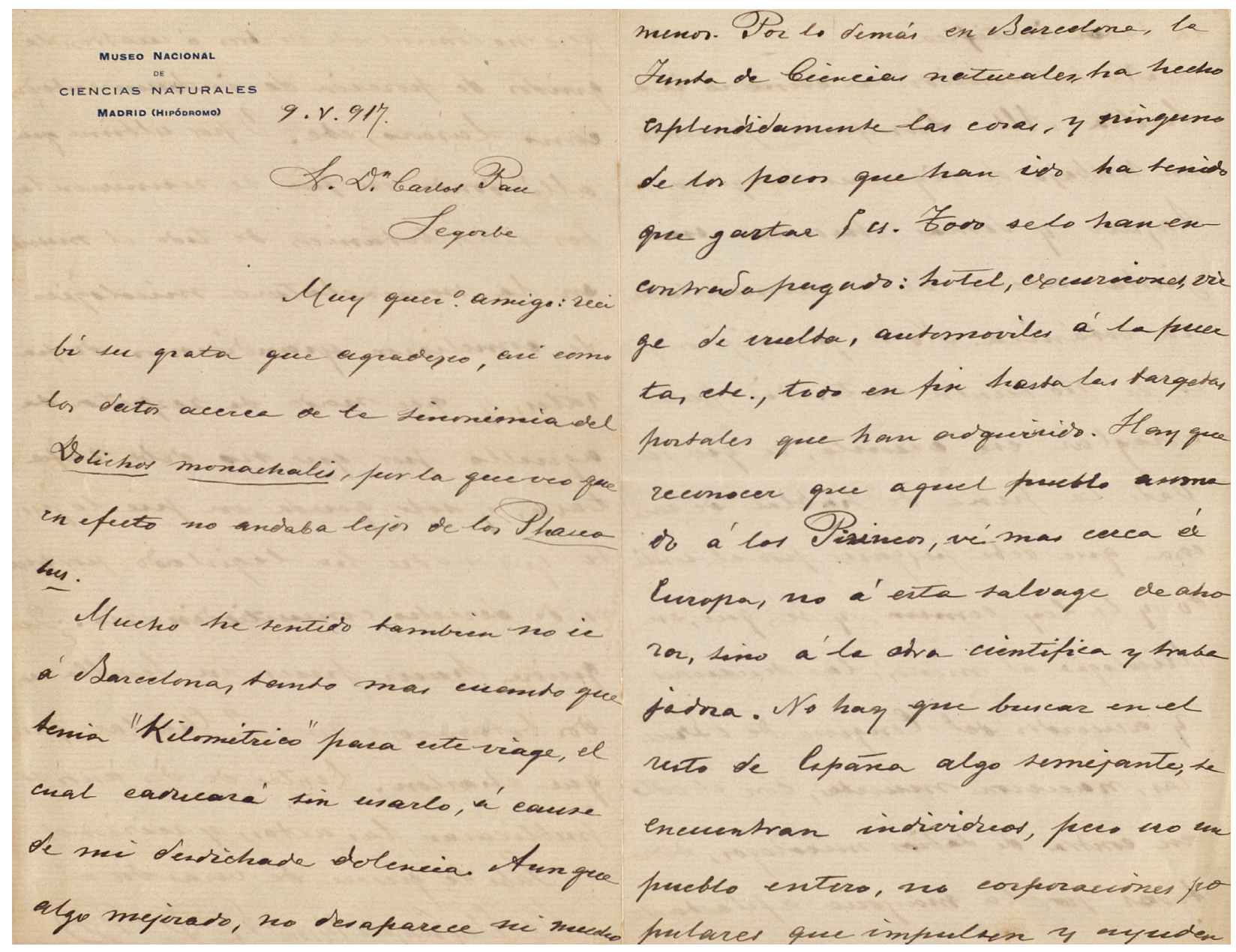

Figura 2. Carta de González Fragoso a Pau del 9 de mayo de 1917. Archivo del Institut Botànic de Barcelona.

a toda prisa tendría que redactar seis páginas y media (González Fragoso 1921: 128-134), sin dispensarse de frases hechas ni calificaciones por entonces tan de moda en ese género! En 1922 — ¿como compensación justísima? - hereda el título de «Socio honorario» que ocupaba el difunto (Anónimo, 1921b: 7, 1922: 7).

Por tratarse de la última comunicación de nuestro epistolario, paso a transcribir una, mecanografiada, que Mateo (1996: 151) vuelve a presentarnos del modo más conciso posible: «Sobre sus trabajos con hongos microscópicos».

\section{MUSEO NACIONAL DE CIENCIAS NATURALES PALACIO DEL HIPÓDROMO MADRID}

$29-X-1925$

Sr. D. Carlos Pau

Segorbe
Mi muy querido amigo: recibi su grata y hoy las plantas, que aun no tuve tiempo de ver siquiera. Le doy gracias por su trabajo ${ }^{16}$, si bien supongo no le darian mucho, pues conoce Vd. muy bien esa flora carpetana, que la naturaleza puso a las puertas de Madrid para que nuestros botánicos la miren desde la Puerta del Sol, o desde alguna Cerveceria. Gracias que Rivas no se le ha ocurrido descubrirla como la de Gredos.

Yo muy mal de salud, pero paso mis dolencias ocupado ahora en estudiar un centenar de hongos de Sto. Domingo que me han enviado en consulta de la Estación Agronómica de Haina, cuyo director el Dr. Ciferri, un buen micologo italiano, no puede determinar falto de libros suficientes. Es una delicia cojer algo de estas floras exóticas, pues ve 


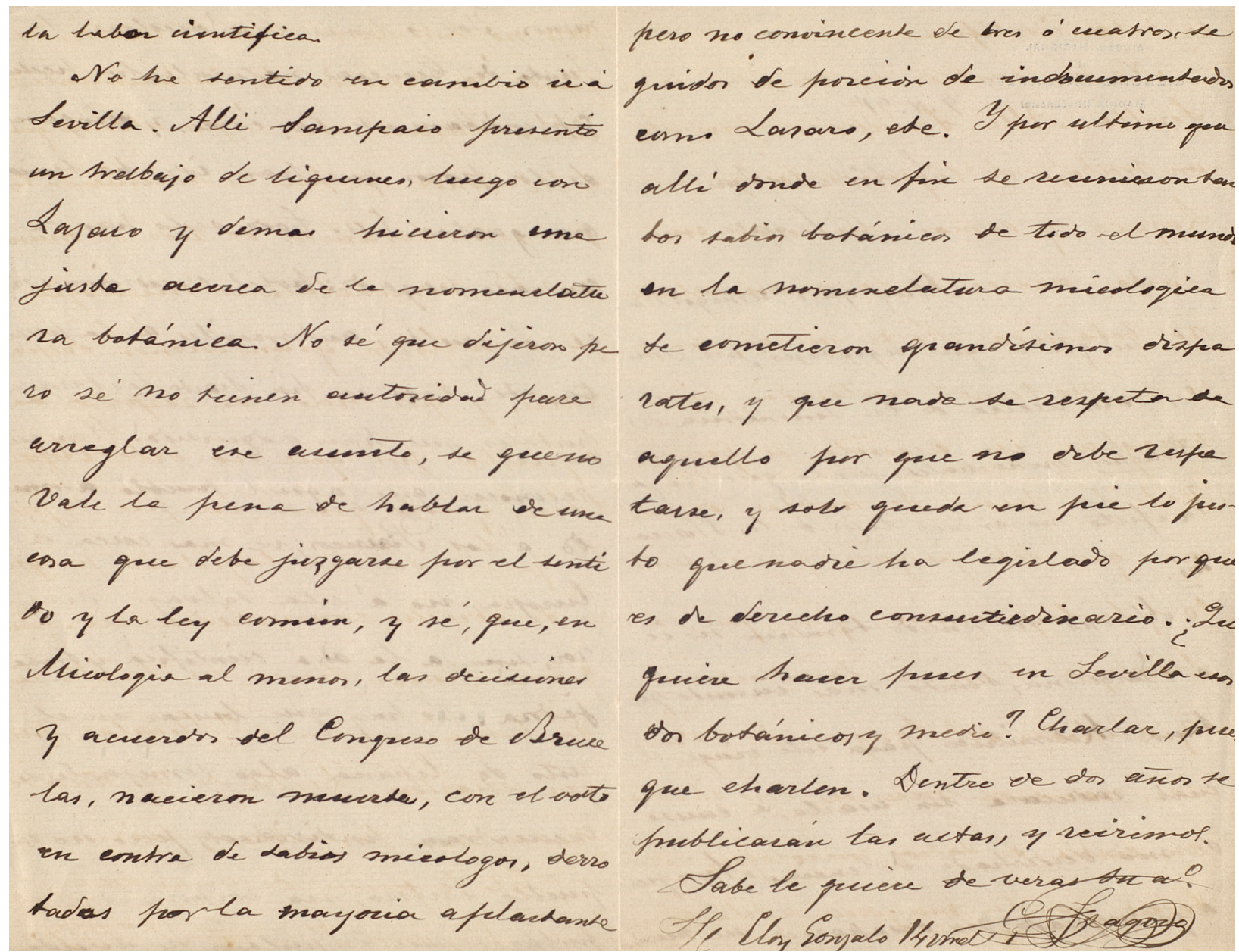

Figura 2. (Cont.)

uno no solo muchas especies nuevas, sino tambien generos y tipos que solo se conocen por algun que otro dibujo, y que son a veces sorprendentes. Quien fuera joven para ir por allá una temporada siquiera. En el próximo numero del Boletin ${ }^{17}$ verá $V d$. la primera serie de ellos.

Es verdad que con esto no gano dinero, como se gana repasando alumnos, pero se disfruta lo indecible, no todos somos rivas, con minuscula.

Tambien he recibido una serie de hongos recolectados por el incomparable Gros, en los cuales hay novedades para nuestra flora. Así es que apesár de que me falta la cooperacion de Caballero y su ayudante, no me escasea trabajo, sino mas bien el tiempo, pues los portugueses tampoco dejan de enviarme.

Supongo le ocurrirá a Vd. lo mismo, y pasará

${ }^{17}$ González Fragoso (1925: 356-368). este invierno entregado a su trabajo habitual, compartido con la Botánica, y vamos viviendo hasta que nos llegue el descanso.

Beltrán me han dicho que en el Discurso inaugural de la Universidad de Valencia habla de todos, y con muchos elogios. No he visto el discurso, pues solo se lo envió a Casares, que, ascendido a Coronel, tuvo que marcharse destinado a la Coruña. Un botánico menos en Madrid.

Le abraza su amigo y verdadero

R. Gon. ${ }^{z}$ Fragoso

[rubricado]

S/c Alvarez de Castro $N^{o} 7$ pral. dcha.

Como epílogo atípico, me permito aquí explicitar que la verdadera mina de información y serias valoraciones referentes a González Fragoso — que tengo delante y a la que vengo acudiendo una y otra vez- es la nota necrológica y bibliográfica firmada por su discípulo el P. Luis María Unamuno, O.S.A. 
(1928), y que me choca el que parezca faltar en Internet. Esta serie - antes de que llegase a Gijón la biblioteca de mi difunto amigo Leroy - hubo de ser consultada por mí en París, ya que no pudo accederse plenamente a ella en la biblioteca del Hortus Regius Matritensis.

\section{AGRADECIMIENTOS}

Se debe toda mi gratitud por su apoyo muy firme al Sr. Director, y a las Sras. Trinitat Prunera y Karina Barros por las múltiples atenciones de que fui objeto por su parte.

\section{REFERENCIAS BIBLIOGRÁFICAS}

Anónimo, 1921a. Sesión del 2 de marzo de 1921. Necrología. Bol. Real Soc. Esp. Hist. Nat. 21: 126.

Anónimo, 1921b. Lista de socios de la Real Española de Historia Natural. Socios honorarios. Bol. Real Soc. Esp. Hist. Nat. 21: 7.

Anónimo, 1922. Lista de socios de la Real Española de Historia Natural. Socios honorarios. Bol. Real Soc. Esp. Hist. Nat. 22: 7.

Castroviejo, S. 1981. LAZAROA (Reseñas bibliográficas). Anales Jard. Bot. Madrid 38: 326-327.

Fernández Riofrío, B. 1928. Romualdo González Fragoso [Necrologías]. Cavanillesia 1: 120-127.

González Bueno, A. 1980. Datos biográficos y bibliográficos del botánico Blas Lázaro e Ibiza. Lazaroa 3: 313-338.

González Fragoso, R. 1914a. Sur quelques champignons peu connus ou nouveaux de la flore espagnole. Bol. Real Soc. Esp. Hist. Nat. 14: 238-243.

González Fragoso, R. 1914b. Varios hongos poco conocidos ó nuevos para la flora española Bol. Real Soc. Esp. Hist. Nat. 14: 429-437.

González Fragoso, R. 1916a. Pugillus secundus mycetorum Persiae. Bol. Real Soc. Esp. Hist. Nat. 16: 167-174.

González Fragoso, R. 1916b. Algunos micromicetos de los alrededores de Melilla (Marruecos) recolectados por el profesor D. A. Caballero. Mem. Real Soc. Esp. Hist. Nat. 8: $335-342$

González Fragoso, R. 1917. Sesión del 3 de Octubre. Bol. Real Soc. Esp. Hist. Nat. 17: 458-460

González Fragoso, R. 1921. D. Blas Lázaro e Ibiza (1856-1921). Bol. Real Soc. Esp. Hist. Nat. 21: 128-134.

González Fragoso, R. 1925. Hongos parásitos y saprófitos de la República Dominicana. Bol. Real Soc. Esp. Hist. Nat. 25: 356-368.

Lázaro, B. 1913. Noticia sobre algunos Ustilagináceos y Uredináceos de España. Trab. Mus. Ci. Nat., Ser. Bot. 2: 1-38.

Lázaro, B. 1916. Los Poliporáceos de la flora española. Revista Acad. Ci. Madrid 14: 427-464, 480-524, 574-592, 655-680, 734-795.

Lázaro, B. 1917. Los Poliporáceos de la flora española. Revista Acad. Ci. Madrid 15: 87-120, 137-184, 209-232, 289-307, 364-369.

Laínz, M. 2001. Algo sobre las relaciones de Pau con Ignacio y Cándido Bolívar. Anales Jard. Bot. Madrid 59: 125-134.

Laínz, M. 2002. Algunos otros documentos o indicaciones de utilidad para la historia de las Ciencias Naturales en España. Anales Jard. Bot. Madrid 60: 163-170.

Mateo, G. 1996. La correspondencia de Carlos Pau: medio siglo de historia de la Botánica española (Monografías de Flora Montiberica, 1) Universitat de València,Valencia.

Pau, C. 1914. Sobre algunos vegetales curiosos. Bol. Soc. Aragonesa Ci. Nat. 13: 42-44.

Pau, C. 1915. Notas sueltas sobre la flora matritense, I. Bol. Soc. Aragonesa Ci. Nat. 14: 204-211, 235-237.

Pau, C. 1916. Notas sueltas sobre la flora matritense, II. Bol. Soc. Aragonesa Ci. Nat. 15: 63-74.

Pau, C. 1924. Notas sueltas sobre la flora matritense, X. Bol. Soc. Ibér. Ci. Nat. 23: 96-107.

Pau, C. \& Vicioso, C. 1918. Plantas de Persia y de Mesopotamia recogidas por D. Fernando Martínez de la Escalera. Trab. Mus. Ci. Nat., Ser. Bot. 14: 3-48.

Ryvarden, L. \& Calonge, F. D. 1976. Type-studies in the Polyporaceae. 5. Species described by Lázaro e Ibiza. Nova Hedwigia 27: 155-164.

Unamuno, L. M. 1928. D. Romualdo González Fragoso (18621928). Noticia necrológica. Conf. Reseñas Ci. Real Soc. Esp. Hist Nat. 3: 81-101. 